\title{
Desempenho e parâmetros sanguíneos de bezerros em sistema de desaleitamento precoce suplementados com probiótico de bactérias ruminais
}

\author{
Performance and blood parameters of calves in early weaning system supplemented \\ with probiotic rumen bacteria
}

\author{
BITTAR, Carla Maris Machado ${ }^{1^{*}}$; SILVA, Fernanda Lavínia Moura ${ }^{1}$; PAULA, Marília \\ Ribeiro de $^{1}$; SILVA, Jackeline Thaís ${ }^{1}$; GALLO, Mariana Pompeo Camargo ${ }^{1}$; \\ OLTRAMARI, Carlos Eduardo ${ }^{1}$; NAPOLES, Gustavo Guilherme Oliveira ${ }^{1}$; SOARES, \\ Marcelo Cezar ${ }^{1}$
}

${ }^{1}$ Universidade de São Paulo, Escola Superior de Agricultura "Luiz de Queiroz", Departamento de Zootecnia, Piracicaba, São Paulo, Brasil.

*Endereço para correspondência: carlabittar@usp.br

\section{RESUMO}

Vinte bezerros mestiços da raça Holandês $\mathrm{x}$ Jersey, distribuídos em blocos completos casualizados, foram utilizados para determinar o efeito do fornecimento de probiótico de bactérias ruminais sobre o desempenho e os parâmetros sanguíneos de bezerros leiteiros em sistema de desaleitamento precoce. Os animais foram submetidos ao tratamento controle ou ao fornecimento via oral de $2 \mathrm{~g}$ de probiótico/dia durante o aleitamento. Os bezerros receberam 6 litros de sucedâneo lácteo por dia divididos em duas refeições diárias e foram desaleitados de forma gradual na $6^{\mathrm{a}}$ semana de vida, entretanto, as variáveis foram coletadas até a $10^{\mathrm{a}}$ semana. $\mathrm{O}$ consumo de concentrado inicial e o escore fecal foram registrados diariamente. Semanalmente foram realizadas pesagens e medidas corporais como, altura de cernelha, largura de garupa e perímetro torácico. Foram realizadas colheitas de sangue nas semanas, 2, 4, 6, 8 e 10, 2h após o primeiro aleitamento, para determinação de concentrações plasmáticas de glicose, proteína total, albumina, $\beta$-hidroxibutirato e cortisol. A suplementação de probiótico não afetou 0 consumo de concentrado, o peso, o ganho de peso, e as medidas corporais dos animais. Não houve efeito sobre o escore fecal entre os tratamentos. Os parâmetros sanguíneos não foram alterados em resposta ao fornecimento do probiótico, apenas a concentração de cortisol, que foi maior nos animais suplementados. O fornecimento de probiótico de bactérias ruminais não favorece o desempenho e o metabolismo de bezerros leiteiros em sistema de desaleitamento precoce.

Palavras-chave: consumo, crescimento, escore fecal, metabolismo

\section{SUMMARY}

Twenty crossbred Holstein x Jersey calves, distributed in a completely randomized block design were used to evaluate the effect of probiotic of ruminal bacteria supply on performance and blood parameters of dairy calves in early weaning system. Animals were submitted to control treatment or supplementation of $2 \mathrm{~g}$ / day of probiotic via milk replacer. The calves received 6 liters of milk replacer per day divided in two daily meals and were gradually early weaned at the $6^{\text {th }}$ week of age, however, all data were collected until $10^{\text {th }}$ week of age. Starter feed intake and fecal score were registered daily. Weekly, body weight, and body measures like, height withers, hip width and heart girth were taken. Blood samples were taken at the $2^{\text {nd }}, 4^{\text {th }}, 6^{\text {th }}, 8^{\text {th }}$ and $10^{\text {th }}$ week, two hours after the morning feeding, to determine plasma concentrations of glucose, total protein, albumin, $\beta$-hydroxybutyrate and cortisol. Probiotic supplementation didn't affect starter feed intake, daily weight gain, weight or body measurements. The probiotic supply also had no effect on fecal scores between treatments. Blood 
Rev. Bras. Saúde Prod. Anim., Salvador, v.17, n.2, p.249-261 abr./jun., 2016 http://www.rbspa.ufba.br ISSN 15199940

parameters were not affect by probiotic supplementation. The probiotic of ruminal bacteria supply present no benefits on the performance or metabolism of dairy calves in early weaning system.

Keywords: fecal score, growth, intake, metabolism

\section{INTRODUÇÃO}

Os sistemas de produção leiteira vêm aumentando a inclusão de aditivos que tenham efeito positivo no desempenho animal (SILVA et al., 2011; SANTOS et al, 2015). O uso de antibióticos como aditivo, para melhorar o desempenho animal, pode tornar bactérias patogênicas mais resistentes e consequentemente difíceis de serem combatidas (MOTA et al., 2005). Deste modo, os probióticos tem sido avaliados como uma alternativa ao uso dos antibióticos.

Probióticos são definidos como suplemento alimentar com microrganismos vivos com efeitos benéficos para o hospedeiro, devido à sua capacidade de melhorar o balanço microbiano intestinal (SANDERS et al., 2008). Os probióticos podem agir como biorreguladores microbianos, mantendo o equilíbrio da microflora intestinal, e impedindo a multiplicação de bactérias patogênicas (LEONARD, 2008).

O fornecimento via oral de probiótico contendo bactérias ruminais (PBR) foi estudado por Ávila et al. (2000) com o objetivo de avaliar os seus benefícios sobre a incidência de diarreia em bezerros na fase de aleitamento. Foi observada redução da incidência de diarreia em até $30 \%$ e aumento do ganho de peso. Timmerman et al. (2005) ao avaliarem o efeito do fornecimento de seis estirpes de Lactobacillus em bezerros, observaram redução na incidência de diarreia e aumento no ganho de peso entre a primeira e a quarta semana de vida dos animais que receberam o tratamento.

Devido ao efeito biorregulador da microflora gastrointestinal, a utilização de PBR visando melhorias no desempenho, pode ser uma boa ferramenta de manejo em sistemas de desaleitamento precoce. A idade de desaleitamento recomendada por USDA (2007) é de 6 a 8 semanas e deve ocorrer quando os bezerros estão consumindo 700 a $900 \mathrm{~g} / \mathrm{d}$. Entretanto, para Bittar et al. (2009), quanto mais cedo ocorre o desaleitamento, menor será o custo da criação para o produtor. Deste modo, o presente estudo teve a finalidade de avaliar o fornecimento de PBR via oral em bezerros leiteiros, sobre $\mathrm{O}$ desempenho e metabolismo sanguíneo dos animais submetidos ao sistema de desaleitamento precoce.

\section{MATERIAL E MÉTODOS}

Este estudo foi realizado no período de dezembro de 2011 a maio de 2012. Todos os procedimentos com os animais experimentais respeitaram as diretrizes recomendadas pela Comissão Interna de Ética Ambiental e Experimentação Animal na mesma instituição.

O experimento foi conduzido no Departamento de Zootecnia da Escola Superior de Agricultura "Luiz de Queiroz", Universidade de São Paulo, localizada em Piracicaba - SP. Foram utilizados 20 bezerros mestiços da raça Holandês x Jersey, os quais foram alojados em uma área experimental composta por brachiaria em terreno plano. Os animais foram distribuídos nos seguintes tratamentos: fornecimento oral de 2 gramas de PBR/dia durante o período de aleitamento (grupo tratado); sem fornecimento de suplemento (grupo 
Rev. Bras. Saúde Prod. Anim., Salvador, v.17, n.2, p.249-261 abr./jun., 2016 http://www.rbspa.ufba.br ISSN 15199940

controle). O PBR, composto por: Bacillus cereus, Enterococcus faecium, Lactobacillus acidophilus, Ruminobacter amylophilum, Ruminobacter succinogenes,

Succinovibrio dextrinosolvens; foi pesado e fornecido individualmente diretamente na cavidade bucal dos bezerros imediatamente antes do fornecimento do sucedâneo.

Após o nascimento, os bezerros foram separados das mães e alocados em abrigos individuais, com acesso à água ad libitum e a concentrado inicial. Os animais receberam 2 litros de colostro após o parto e posteriormente a cada 12 horas até o segundo dia de vida. Decorrido o período de fornecimento de colostro, os animais passaram a receber 6 litros de sucedâneo lácteo (Sprayfo Violeta, Sloten do Brasil Ltda., Santos, SP, Brasil), divididos em duas refeições diárias $(08$ e 18h). A composição bromatológica do sucedâneo foi: 97,4\% de $\mathrm{MS}, 8,2 \%$ de $\mathrm{MM}, 20,2 \%$ de $\mathrm{PB}$, $15,6 \%$ de EE, $55,5 \%$ de CNF e $0,5 \%$ de FDN. O desaleitamento foi realizado na $6^{\text {a }}$ semana de idade de forma gradual, entretanto, os bezerros continuaram no experimento até a $10^{\mathrm{a}}$ semana de vida.

$\mathrm{O}$ concentrado inicial era quantificado e fornecido diariamente (Tabela 1). A sobra do dia anterior era pesada, de forma a se obter o consumo de concentrado. A quantidade máxima oferecida por animal foi de até $2 \mathrm{~kg} / \mathrm{dia}$. A partir do desaleitamento, foi fornecido feno de capim coast-cross ad libitum, além do concentrado inicial, sendo eles quantificados antes do fornecimento. A sobra do dia anterior era pesada, de forma a se obter $\mathrm{o}$ consumo de concentrado e feno.

Os animais foram pesados ao nascer e semanalmente, sempre antes do fornecimento do leite da manhã, em balança mecânica (ICS-300, Coimma Ltda., Dracena, SP, Brasil), até a $10^{\mathrm{a}}$ semana de vida, para calcular o ganho de peso. Foram também mensuradas semanalmente a altura da cernelha e a largura da garupa, utilizando-se régua com escala em centímetros; e o perímetro torácico com fita, também com escala em centímetros.

Tabela 1. Ingredientes e composição química-bromatológica do concentrado inicial utilizado na alimentação dos animais

\begin{tabular}{|c|c|}
\hline Ingredientes & $\begin{array}{c}\text { Composição } \\
(\%)\end{array}$ \\
\hline Milho moído & 64,0 \\
\hline Farelo de soja & 26,0 \\
\hline Casca de soja & 6,0 \\
\hline Calcário calcítico & 3,0 \\
\hline Premix mineral/vitamínico ${ }^{1}$ & 1 \\
\hline \multicolumn{2}{|c|}{ Composição química-bromatológica } \\
\hline $\begin{array}{llll}\begin{array}{l}\text { Matéria } \\
\text { natural }^{2}\end{array} & \text { seca, } \% & \text { matéria } \\
\end{array}$ & 89,95 \\
\hline Matéria mineral, $\% \mathrm{MS}^{2}$ & 5,88 \\
\hline Proteína bruta, $\% \mathrm{MS}^{2}$ & 20,6 \\
\hline Extrato etéreo, $\% \mathrm{MS}^{2}$ & 3,4 \\
\hline FDN, $\% \mathrm{MS}^{2}$ & 13,13 \\
\hline FDA, $\% \mathrm{MS}^{2}$ & 6,92 \\
\hline $\begin{array}{l}\text { Energia metabolizável, } \\
\mathrm{Mcal} / \mathrm{kg}^{3}\end{array}$ & 2,94 \\
\hline $\begin{array}{l}{ }^{1} \text { Composição } \\
\text { mineral/vitamínico: Ca } 16,8 \\
\text { 2,3\%; Na } 11,6 \% \text { Cl } 8,0 \% \text { M } \\
\text { ppm; Cu } 343 \text { ppm; I } 30,2 \mathrm{p} \\
\text { ppm; Mn 1146,4 ppm; Se } \\
1176,2 \text { ppm; Vit. A } 68.760 \\
764 \mathrm{UI} / \mathrm{kg} \text {; Vit. D 57.300 UI/1 } \\
{ }^{2} \text { Valores obtidos com base } \\
\text { das análises bromatol } \\
\text { ingredientes. } \\
{ }^{3} \text { Valor estimado pelo NRC (2 }\end{array}$ & $\begin{array}{l}\text { Premix } \\
\mathrm{P} 4,2 \% ; \mathrm{S} \\
2,4 ; \mathrm{Co} 38,2 \\
\mathrm{~m} ; \mathrm{Fe} 578,2 \\
, 5 \mathrm{ppm} \text { Zn } \\
\mathrm{I} / \mathrm{kg} \text {; Vit. E } \\
\text { ricas dosultados } \\
\text { 1). }\end{array}$ \\
\hline
\end{tabular}

Diariamente, foram realizadas avaliações do escore fecal de todos os animais conforme Larson et al. (1977), sendo classificadas conforme a fluidez: (1) quando normais e firmes; (2) quando com consistência pastosa porém com aspecto geral saudável; (3) quando 
Rev. Bras. Saúde Prod. Anim., Salvador, v.17, n.2, p.249-261 abr./jun., 2016 http://www.rbspa.ufba.br ISSN 15199940

com consistência aquosa considerada diarreia; (4) quando com consistência fluída.

Amostras de sangue foram colhidas na $2^{\mathrm{a}}, 4^{\mathrm{a}}, 6^{\mathrm{a}}, 8^{\mathrm{a}}$ e $10^{\mathrm{a}}$ semanas de vida dos animais, sempre duas horas após o fornecimento da dieta líquida no período da manhã, através de punção da veia jugular, utilizando-se tubos tipo Vacutainer ${ }^{\circledR}$ com Fluoreto de sódio e EDTA K3. As amostras foram submetidas à centrifugação a $2000 \times \mathrm{g}$, durante 20 minutos, à temperatura de $4^{\circ}$ C. O plasma foi armazenado em microtubos e mantidos a $-18^{\circ} \mathrm{C}$ para posterior determinação de cortisol, glicose, $\beta$-hidroxibutirato, proteína total e albumina. A concentração de cortisol se deu por meio do método de imunoensaio competitivo, com determinação quantitativa de cortisol em fluidos biológicos, através do kit comercial (Assay Designs, EUA). As determinações da concentração de glicose, $\beta$-hidroxibutirato, proteína total e albumina foram realizadas em Sistema Automático para Bioquímica - Modelo SBA-200 (CELM) com a utilização de kit enzimático de glicose (Glicose HK LIQUIFORM - Ref::85, LABTEST Diagnóstica $\quad$ S.A.), $\beta$-hidroxibutirato (RANBUT - Ref.: RB1007, Randox Laboratories), proteínas totais (Proteínas totais - Ref: 99-250, LABTEST Diagnóstica S.A.) e albumina (Albumina - Ref: 19, LABTEST Diagnóstica S.A., Lagoa Santa, MG, Brasil).

O delineamento experimental utilizado foi o de blocos completos casualizados, de acordo com o peso ao nascimento e sexo. As análises estatísticas foram realizadas utilizando o MIXED do SAS versão 9.4 (SAS Institute, 2013), e considerado efeito significativo quando $\mathrm{P}<0,05$. Os dados de peso, consumo de concentrado, ganho de peso, medidas corporais, escore fecal e parâmetros sanguíneos foram analisados como medidas repetidas no tempo, conforme o modelo: Yijk $=\mu+\mathrm{Bi}+\mathrm{Tj}+\mathrm{Ik}+$ BIik + TIjk + Eijk, onde, Yijk $=$ variável resposta; $\mu=$ média geral; $\mathrm{Bi}=$ efeito do bloco; $\mathrm{Tj}=$ efeito do tratamento (com ou sem suplementação com PBR); Ik = efeito de idade dos animais (semana); Blik = efeito de interação entre bloco e idade dos animais; TIjk = efeito de interação entre tratamento e idade dos animais; Eijk = erro residual. Os dados de peso, consumo de concentrado e ganho de peso foram analisadas conforme $o$ modelo: $Y i j k=\mu+B i+T j+$ Eij, sendo Yijk $=$ variável resposta; $\mu=$ média geral; $\mathrm{Bi}=$ efeito de bloco; $\mathrm{Tj}=$ efeito do tratamento e Eijk = erro residual. $\mathrm{O}$ efeito de tratamento foi definido pelo teste $\mathrm{F}$ da análise de variância.

\section{RESULTADOS E DISCUSSÃO}

$\mathrm{O}$ fornecimento de $\mathrm{PBR}$ não afetou $(\mathrm{P}>0,05)$ o consumo de concentrado inicial, o peso corporal, nem o ganho de peso em todo o período experimental (Tabela 2). Fornecer PBR para bezerros em aleitamento estabelece e mantém estável os microrganismos intestinais, resultando em melhor desempenho, principalmente quando animais jovens passam por algum estresse que pode alterar a população microbiana do trato gastrointestinal (KREHBIEL et al., 2003). Apesar do desaleitamento precoce ser considerado fator de estresse para os bezerros (KELLEY, 1980), a utilização de PBR não promoveu melhora as variáveis citadas, possivelmente devido à falta de eficácia das espécies bacterianas do PBR, que são diferentes das comumente utilizadas nos probióticos (MATOS, 2008). 
Rev. Bras. Saúde Prod. Anim., Salvador, v.17, n.2, p.249-261 abr./jun., 2016 http://www.rbspa.ufba.br ISSN 15199940

Tabela 2. Desempenho de bezerros suplementados ou não com PBR via oral

\begin{tabular}{lcccccc}
\hline \multirow{2}{*}{ Item } & \multicolumn{3}{c}{ Tratamento } & \multirow{2}{*}{$\mathrm{EPM}^{(1)}$} & \multicolumn{3}{c}{$\mathrm{P}<<^{(2)}$} \\
\cline { 2 - 3 } \cline { 7 - 8 } & Controle & PBR & & $\mathrm{T}$ & $\mathrm{I}$ & $\mathrm{TxI}$ \\
\hline Peso corporal, kg & & & & & & \\
\hline Nascimento & 38,6 & 39,2 & 1,98 & 0,81 & --- & --- \\
Ao desaleitamento & 44,21 & 44,17 & 1,98 & 0,99 & --- & -- \\
Período experimental & 45,7 & 45,8 & 1,83 & 0,97 & $<, 0001$ & 0,95 \\
\hline Consumo de concentrado, g/dia & & & & & & \\
\hline Ao desaleitamento & 341 & 418 & 71,18 & 0,45 & --- & --- \\
Período experimental & 768 & 753 & 40,12 & 0,80 & $<, 0001$ & 0,28 \\
\hline Ganho de peso, g/dia & & & & & & \\
\hline Ao desaleitamento & 255 & 223 & 76,91 & 0,77 & --- & --- \\
Período experimental & 324 & 327 & 29,91 & 0,94 & $<, 0001$ & 0,91 \\
\hline
\end{tabular}

${ }^{\mathrm{T}}$ EPM: erro padrão da média; ${ }^{2} \mathrm{~T}=$ efeito de tratamentos; $\mathrm{I}=$ efeito de idade dos animais; $\mathrm{TxI}=$ interação entre tratamento e idade.

Batista et al. (2008) ao utilizarem Lactobacillus acidophillus, Enterococus faecium e Bifidobacterium bifidum não observaram efeito positivo da suplementação de probiótico sobre o consumo de concentrado e o ganho de peso dos bezerros. No entanto, Timmerman et al. (2005) observaram que animais suplementados com probióticos da espécie Lactobacillus obtiveram resultados positivos em relação ao peso corporal durante as duas primeiras semanas de vida, ao ganho de peso durante as oito primeiras semanas de vida e melhora no peso corporal depois da $8^{\mathrm{a}}$ semana de vida dos animais. Resultados semelhantes foram observados por Cruywagen et al. (1996), onde animais recebendo probiótico L. acidophilus apresentaram maior ganho de peso em relação aos animais controle, nas duas primeiras semanas de vida. Adicionalmente, os animais controle tiveram perda de $4 \%$ do peso inicial na segunda semana de vida, enquanto os animais recebendo probiótico perderam apenas $0,8 \%$ do peso inicial.

Em estudo realizado por Rincker et al. (2011) foi demonstrado que quanto maior o volume de dieta liquida fornecida, menor o consumo de dieta sólida. Possivelmente devido ao maior aporte de energia metabolizável advinda do sucedâneo (KHAN et al., 2007). Entretanto, apesar do consumo de concentrado inicial no período de aleitamento ter se apresentado abaixo do observado em outros trabalhos (HILL et al., 2009; SILVA et al., 2011) (Figura 1), os animais do grupo tratado conseguiram atingir recomendações tradicionais de consumo ao desaleitamento de acordo com Greenwood et al. (1997), que consiste no desaleitamento de bezerros consumindo o equivalente a $1,0 \%$ do seu peso vivo ao nascimento, sem causar efeitos negativos. Os animais não suplementados foram desaleitados consumindo apenas $0,88 \%$ do seu peso ao nascimento, entretanto, os parâmetros de desempenho animal não foram afetados.

Embora o fornecimento de probiótico evite a perda de peso em animais durante as duas primeiras semanas de vida (TIMMERMAN et al., 2005), os animais do presente estudo apresentaram uma leve queda do peso corporal na segunda semana (Figura 2). Este fato se deve 
Rev. Bras. Saúde Prod. Anim., Salvador, v.17, n.2, p.249-261 abr./jun., 2016 http://www.rbspa.ufba.br ISSN 15199940

possivelmente a maior ocorrência de distúrbios gastrointestinais como a diarreia, bastante frequente nessa idade, diminuindo o consumo e provocando perda de peso nos bezerros (SILVA et al., 2011).

Algumas cepas probióticas podem auxiliar na eliminação de bactérias patogênicas do intestino, causadoras da diarreia, seja por ação de bacteriocinas, ou por exclusão competitiva, impedindo que tais bactérias colonizem a mucosa intestinal e produzam suas toxinas. Assim, auxiliando na saúde e consequentemente no desempenho dos bezerros (KREHBIEL et al., 2003). Eventualmente, o tipo das cepas presentes no $\mathrm{PBR}$ não foram eficazes em auxiliar na eliminação bactérias causadoras da diarreia.

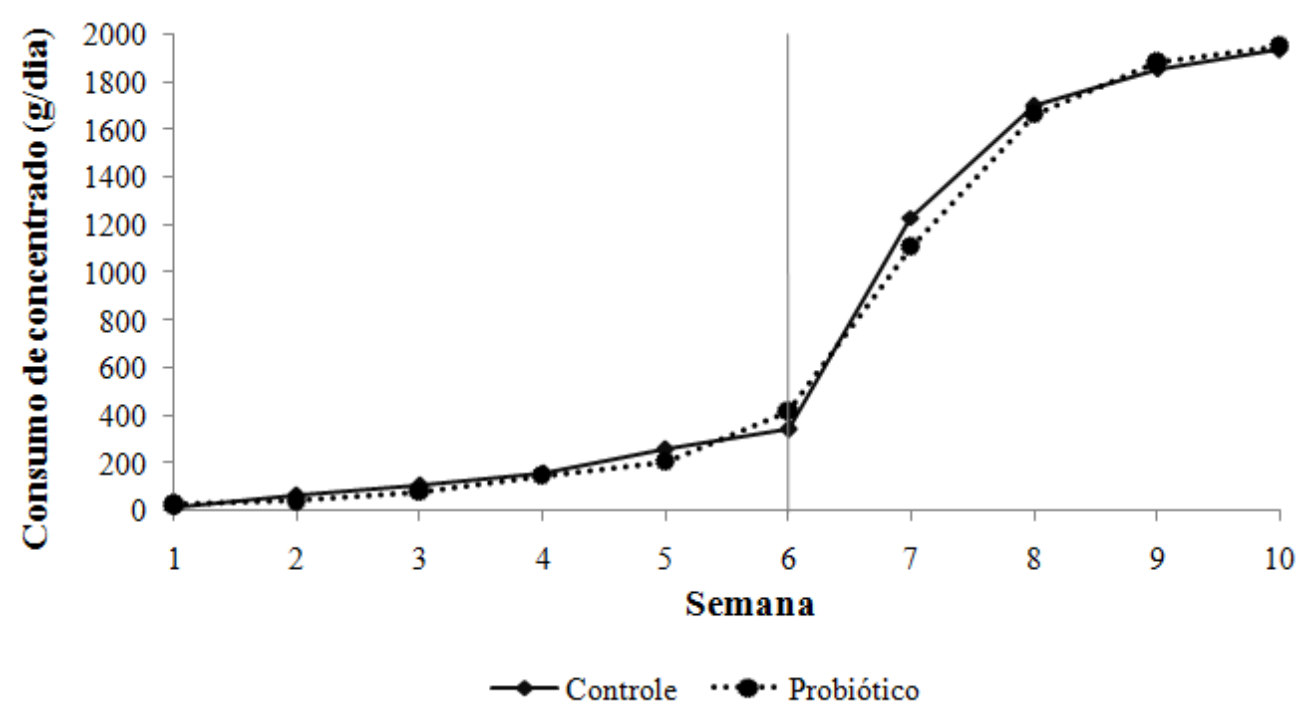

Figura 1. Consumo de concentrado (g/dia), de acordo com a idade, por bezerros suplementados ou não com probióticos via oral

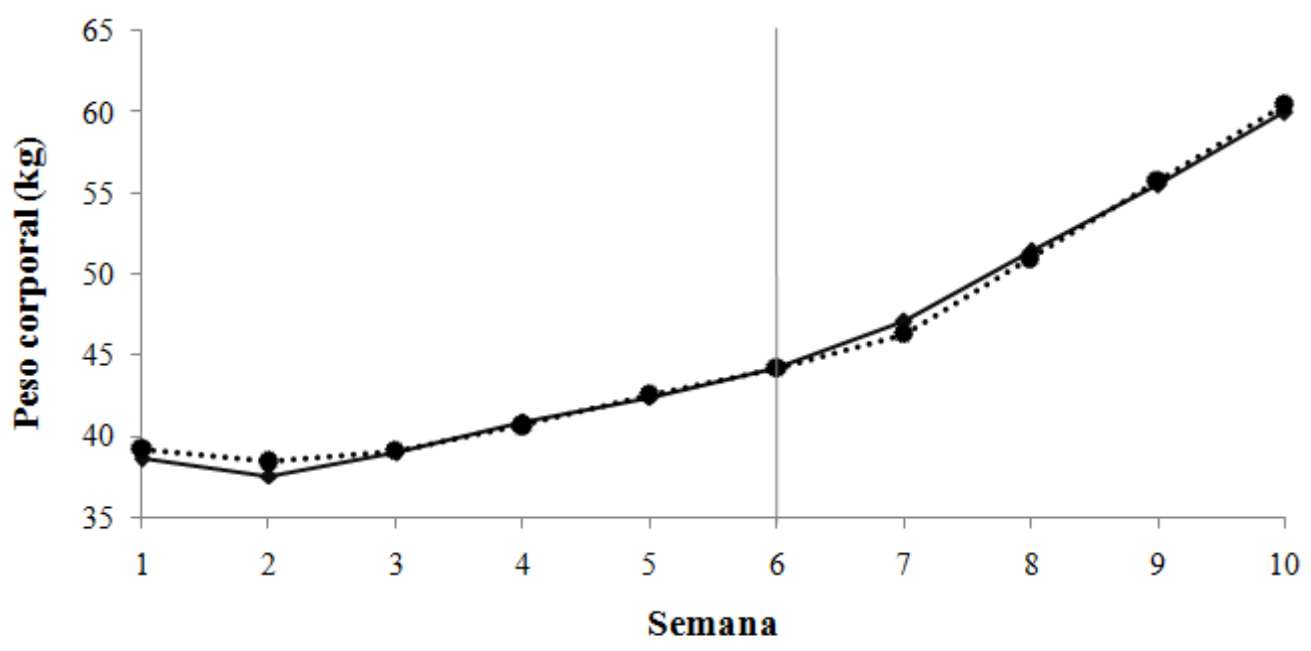

Figura 2. Peso corporal (kg), de acordo com a idade, por bezerros suplementados ou não com probióticos via oral 
Rev. Bras. Saúde Prod. Anim., Salvador, v.17, n.2, p.249-261 abr./jun., 2016 http://www.rbspa.ufba.br ISSN 15199940

As medidas corporais obtidas neste estudo estão apresentadas na Tabela 3. Como é possível observar, não houve efeito $(\mathrm{P}>0,05)$ da suplementação com probiótico nas medidas de perímetro torácico, altura de cernelha e largura de garupa. Tanto os animais recebendo probióticos como os animais do grupo controle obtiveram um crescimento positivo contínuo de acordo com a evolução da idade dos animais. Resultados semelhantes foram encontrados em estudo realizado por Jenny et al. (1991) o qual não foi possível mostrar efeitos benéficos do uso do probiótico sobre o crescimento dos bezerros.

Tabela 3. Medidas corporais de bezerros suplementados ou não com PBR em todo período experimental

\begin{tabular}{|c|c|c|c|c|c|c|}
\hline \multirow{2}{*}{ Item } & \multicolumn{2}{|c|}{ Tratamento } & \multirow{2}{*}{$\mathrm{EPM}^{(1)}$} & \multicolumn{3}{|c|}{$\mathrm{P}<{ }^{(2)}$} \\
\hline & Controle & PBR & & $\mathrm{T}$ & I & TxI \\
\hline Perímetro torácico $(\mathrm{cm})$ & 81,56 & 82,15 & 0,79 & 0,61 & $<, 0001$ & 0,96 \\
\hline Altura na cernelha $(\mathrm{cm})$ & 78,92 & 78,97 & 0,91 & 0,96 & $<, 0001$ & 0,45 \\
\hline Largura da garupa $(\mathrm{cm})$ & 21,78 & 21,61 & 0,30 & 0,62 & $<, 0001$ & 0,30 \\
\hline
\end{tabular}

${ }^{1}$ EPM: erro padrão da média; ${ }^{2} \mathrm{~T}$ = efeito de tratamentos; $\mathrm{I}=$ efeito de idade dos animais; TxI = interação entre tratamento e idade.

Embora se esperasse que a suplementação com probiótico causasse diminuição na ocorrência de diarreias nos bezerros, não foi observado este efeito $(\mathrm{P}>0,05)$ nos animais do grupo tratado no período de aleitamento (Figura 3).

Estudo realizado por Timmerman et al. (2005), demonstrou que o uso de probióticos reduz a incidência e $\mathrm{o}$ número médio de dias com diarreia em animais, consequentemente diminuindo a taxa de mortalidade. Entretanto, segundo Constable (2009) não existem evidências que apoiem a eficácia de probióticos em bezerros que já se apresentem em quadros de diarreia, não sendo recomendado neste momento.

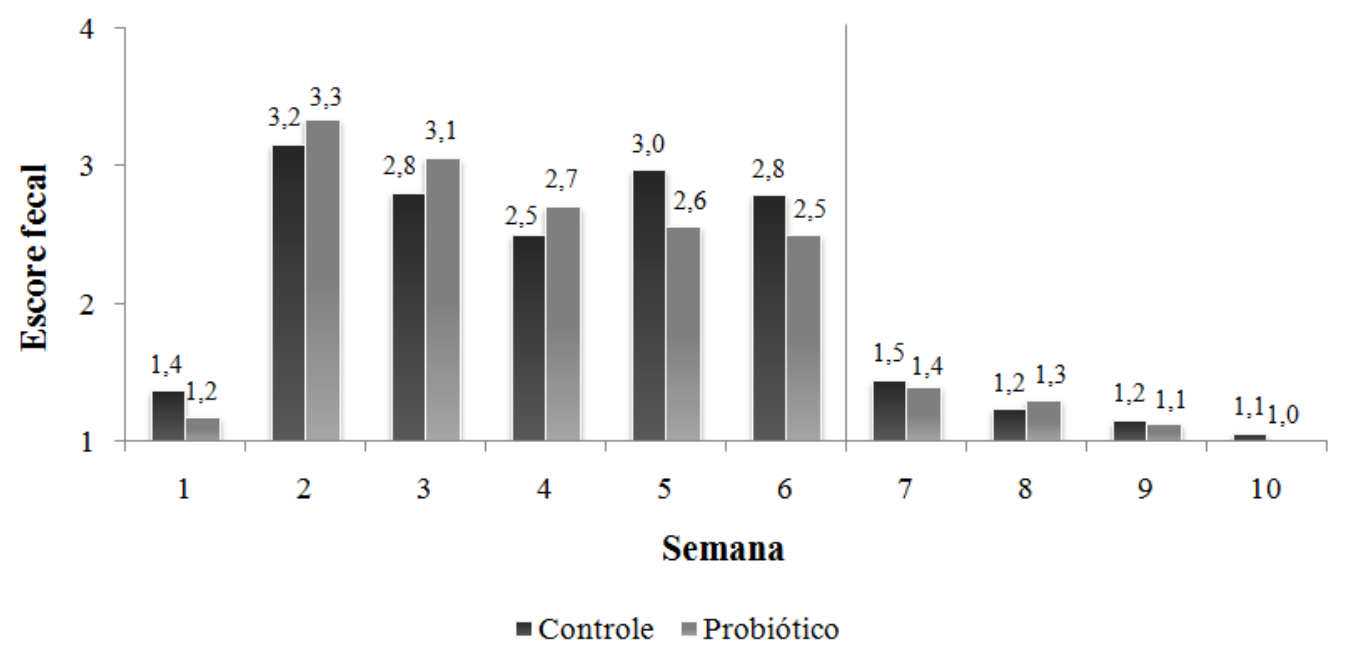

Figura 3. Escore fecal de bezerros suplementados ou não com probióticos via oral 
Rev. Bras. Saúde Prod. Anim., Salvador, v.17, n.2, p.249-261 abr./jun., 2016 http://www.rbspa.ufba.br ISSN 15199940

A ocorrência de diarreia em bezerros é comum entre a segunda e terceira semana de idade (MILLEMANN, 2009). Entretanto no presente estudo, o escore fecal se apresentou alto da segunda a sexta semana de vida dos bezerros. A diarreia em bezerros possui etiologia multifatorial, podendo incluir fatores infecciosos, ambientais, nutricionais e fatores de gestão (GULLIKSEN et al., 2009). Deste modo, provavelmente esse alto índice de diarreia seja consequência da quantidade de dieta líquida que os animais consumiam (6 litros/dia ou $\cong 15,4 \%$ do peso corporal ao nascer/dia). Alguns autores sugerem que bezerros que recebem grande quantidade de dieta líquida apresentam fezes mais fluídas durante $o$ período de aleitamento (BROWN et al., 2005).

Não houve efeito da suplementação do PBR sobre a concentração plasmática de glicose $(\mathrm{P}>0,05)$ (Tabela 4). Alguns autores relataram valores médios de glicose plasmática para bezerros holandeses em torno de 70 a $90 \mathrm{mg} / \mathrm{dL}$ (BERNARDES et al., 2007; SHINGU et al., 2007; BITTAR et al., 2009).

Tabela 4. Concentrações plasmáticas de glicose, $\beta$-hidroxibutirato ( $\beta \mathrm{HBA}$ ), proteínas totais, albumina e cortisol de bezerros suplementados ou não com PBR em todo período experimental

\begin{tabular}{|c|c|c|c|c|c|c|}
\hline \multirow{2}{*}{ Item } & \multicolumn{2}{|c|}{ Tratamento } & \multirow{2}{*}{$\mathrm{EPM}^{(1)}$} & \multicolumn{3}{|c|}{$\mathrm{P}<{ }^{(2)}$} \\
\hline & Controle & Probiótico & & $\mathrm{T}$ & I & TxI \\
\hline Glicose, mg/dL & 81,08 & 77,96 & 2,34 & 0,30 & $<, 0001$ & 0,17 \\
\hline$\beta \mathrm{HBA}, \mathrm{mmol} / \mathrm{L}$ & 0,196 & 0,213 & 0,02 & 0,48 & $<, 0001$ & 0,86 \\
\hline Proteínas totais, $\mathrm{mg} / \mathrm{dL}$ & 6,31 & 6,40 & 0,17 & 0,72 & $<, 0001$ & 0,72 \\
\hline Albumina, mg/dL & 2,81 & 2,85 & 0,07 & 0,68 & $<, 0001$ & 0,88 \\
\hline Cortisol, $\mu \mathrm{g} / \mathrm{dL}$ & 1,11 & 1,31 & 0,07 & 0,05 & 0,16 & 0,22 \\
\hline
\end{tabular}

${ }^{1}$ EPM: erro padrão da média; ${ }^{2} \mathrm{~T}=$ efeito de tratamentos; $\mathrm{I}=$ efeito de idade dos animais; $\mathrm{TxI}=$ interação entre tratamento e idade.

A concentração plasmática de glicose apresentou comportamento decrescente com o avanço da idade dos animais, sendo essa queda possivelmente devido à transição dos animais de pré-ruminante para ruminantes funcionais. Segundo Hayashi et al. (2006), bezerros na fase de pré-ruminante possuem uma digestão semelhante à de monogástricos, onde a dieta liquida consumida é absorvida pelo intestino e metabolizada transformando lactose em glicose circulante. Com o desenvolvimento das funções do rúmen e aumento da população de microrganismos ruminais, há um aumento da produção de ácidos graxos de cadeia curta, as quais se tornam a fonte principal de energia para os bezerros. Com isso há uma modificação no metabolismo, com diminuição da capacidade de absorção de glicose pelo intestino delgado.

As concentrações plasmáticas de $\beta$ hidroxibutirato não apresentaram diferença significativa $(\mathrm{P}>0,05)$ entre os grupos experimentais (Tabela 4). $\mathrm{O}$ fornecimento de bactérias ruminais, via oral para bezerros, deveria proporcionar ao rúmen um ambiente mais adequado à um desenvolvimento precoce, devido as bactérias do probiótico serem responsáveis pela fermentação de alimentos sólidos ingeridos. Entretanto, o estudo não observou efeito benéfico possivelmente devido ao baixo consumo de concentrado de ambos os grupos experimentais. Para que o rúmen se desenvolva e comece a produzir AGCC e 
estabilizar a microflora, é preciso que o animal pré-ruminante comece a consumir matéria seca proveniente de dieta sólida, de preferência alimento concentrado devido ao seu perfil de fermentação (QUIGLEY et al., 1991).

Os animais suplementados com PBR e os animais do grupo controle apresentaram valores crescentes de $\beta$-hidroxibutirato com o passar do tempo. Coverdale et al. (2004) obtiveram resultados semelhantes, com média do período total menor que $0,20 \mathrm{mmol} / \mathrm{dL}$ antes do desaleitamento e maior no período após o desaleitamento. O $\beta$-hidroxibutirato é um forte parâmetro para estimar o desenvolvimento do rúmen, uma vez que bezerros vão se tornando ruminantes funcionais com $\mathrm{o}$ avançar da idade e com o aumento do consumo de alimentos sólidos, começam a utilizar os AGCC como principal fonte de energia, metabolizando-os em corpos cetônicos. Esse fato se torna mais acentuado após o desaleitamento (HAGA et al., 2008).

As concentrações de proteínas plasmáticas totais não foram afetadas de forma significativa $(\mathrm{P}>0,05)$ em resposta à suplementação de PBR via oral (Tabela 4). Corroborando com este resultado, Morrill et al. (1995) utilizando suplemento probiótico no leite, também não observaram efeito sobre as concentrações de proteína plasmática total.

As concentrações de proteínas plasmáticas totais tiveram valores crescentes com o passar do tempo. Conforme Costa et al. (2007) e Costa et. al. (2008), logo após o nascimento do bezerro as concentrações de proteína total no sangue são baixas devido à baixa concentração de globulina ao nascer. Com a ingestão de colostro ocorre um rápido aumento da fração de globulina, acarretando no aumento da concentração de proteína total. Conforme a idade do animal avança, sua capacidade endógena de produção de globulina se torna cada vez mais elevada, consequentemente os valores de proteínas totais são crescentes com a idade.

As concentrações de albumina não foram afetadas de forma significativa $(\mathrm{P}>0,05)$ pela suplementação de PBR. No entanto, foi observado efeito significativo de idade nas concentrações de albumina $(\mathrm{P}>0,0001)$, se mantendo constante durante o período de aleitamento e se elevando após o desaleitamento, corroborando com Lima et al. (2012). A albumina compreende em torno de $60 \%$ das proteínas presentes no plasma, diminuindo sua porcentagem em relação a proteínas totais de acordo com o avanço etário dos animais, devido a uma maior produção de imunoglobulinas (MOTTA, 2009). Suas funções no organismo são várias, dentre as mais importantes está a contribuição do efeito osmótico do plasma e transporte e armazenamento de várias substâncias pouco solúveis em água, como o cálcio e alguns hormônios, que são regulados, de certa forma, pela albumina (MOTTA, 2005).

A concentração plasmática de cortisol do grupo que recebeu PBR foi maior $(\mathrm{P}=0,05)$ em relação ao grupo controle (Tabela 4). Este resultado se deve possivelmente ao fato do fornecimento via oral do PBR ter sido apenas para o grupo tratado. Segundo Snel-Oliveira et al. (2013), animais envolvidos em pesquisa são passíveis de serem influenciados pelo estresse provocado pela manipulação dos animais. $\mathrm{O}$ estresse é um dos principais fatores que estimulam o córtex e a medula adrenal a sintetizar hormônios relacionados, como o cortisol (PAES et al., 2012). Entretanto, os níveis de cortisol dos animais dos diferentes grupos apresentaram valores dentro da normalidade (YARI et al., 2010)

Penha et al. (2011) avaliou a concentração de cortisol sérico em bovinos submetidos a estresse recebendo 
Rev. Bras. Saúde Prod. Anim., Salvador, v.17, n.2, p.249-261 abr./jun., 2016 http://www.rbspa.ufba.br ISSN 15199940

e não recebendo probióticos composto por bactérias Lactobacillus acidophilus, Estreptococus faecium, Bifedobacterium thermoplhilum e Bifedobacterium longum. Os animais do grupo controle, após exposição a agentes estressores tiveram níveis de cortisol sérico maiores em 22,8\% em comparação aos animais recebendo probiótico. Já em trabalho realizado por Ballou (2011), o fornecimento de probiótico não teve efeito significativo em relação ao nível de cortisol sérico em relação aos animais do grupo controle.

Ao desaleitamento ( $6^{\text {a }}$ semana) houve uma concentração de cortisol sérico maior em comparação à $4^{\mathrm{a}}$ e $8^{\mathrm{a}}$ semana, provavelmente em consequência ao estresse do desaleitamento. Para bezerros o desaleitamento é um dos fatores mais estressantes, devido a mudança abrupta da dieta (HALEY et al., 2005; ENRÍQUEZ et al., 2010).

As avaliações de desempenho e as análises sanguíneas realizadas neste estudo sugerem que o fornecimento via oral de PBR para bezerros em período de aleitamento não apresenta benefícios aos bezerros leiteiros aleitados e após $\mathrm{o}$ desaleitamento.

\section{REFERÊNCIAS}

ÁVILA, F.A.; PAULILLO, A.C.; SCHOCKEN-ITURRINO, R.P.; LUCAS, F.A.; ORGAZ, A.; QUINTANA, J.L. Avaliação da eficiência de um probiótico no controle de diarreia e no ganho de peso de bezerros. Arquivo Brasileiro de Medicina Veterinária e Zootecnia, v.52, n.1, p.41-46, 2000.

BALLOU, M.A. Case study: effects of a blend of prebiotics, probiotics, and hyperimmune dried egg protein on the performance, health, and innate immune responses of Holstein calves. The

Professional Animal Scientist, v.27, p.262-268, 2011.

BATISTA, C.G.; COELHO, S.G.; RABELO, E; LANA, A.M.Q; CARVALHO, A.U.; REIS, R.B.; SATURNINO, H.M. Desempenho e saúde de bezerros alimentos com leite sem resíduo de drogas antimicrobianas ou leite de vacas tratadas contra mastite adicionado ou não de probiótico.

Arquivo Brasileiro de Medicina Veterinária e Zootecnia, v.60, p.185191, 2008.

BERNARDES, E.B.; COELHO, S.G.; CARVALHO, A.U.; OLIVEIRA, H.N.; REIS, R.B.; SATURNINO, H.M.; SILVA, C.A.; COSTA, T.C. Efeito da substituição do feno Tifton 85 pelo caroço de algodão como fonte de fibra na dieta de bezerros. Arquivo Brasileiro de Medicina Veterinária e Zootecnia. Belo Horizonte, v.59, n.4, p.955-964, 2007.

BITTAR, C.M.M.; FERREIRA, L.S.; SANTOS, F.A.P.; ZOPOLLATTO, M. Desempenho e desenvolvimento do trato digestório superior de bezerros leiteiros alimentados com concentrado de diferentes formas físicas. Revista Brasileira de Zootecnia, v.38, n.8, p.1561-1567, 2009.

BROWN, E. G.; VANDEHAAR, M.J.; DANIELS, K.M.; LIESMAN, J.S.; CHAPIN, L.T.; KEISLER, D.H.; WEBER NIELSEN, M.S. Effect of increasing energy and protein intake on body growth and carcass composition of heifer calves. Journal of Dairy Science, v.88, n.8, p.585-594, 2005.

CONSTABLE, P.D. Treatment of calf diarrhea: Antimicrobial and ancillary treatments. Veterinary Clinics Food Animal Practice, v. 25, p.101-120, 2009. 
Rev. Bras. Saúde Prod. Anim., Salvador, v.17, n.2, p.249-261 abr./jun., 2016 http://www.rbspa.ufba.br ISSN 15199940

COSTA, J.N.; PEIXOTO, A.P.C.; KOHAYAGAWA, A.; SOUZA, T.S. Proteinograma sérico de bezerras da raça Holandesa do nascimento aos 150 dias de idade. Revista Brasileira de Saúde e Produção Animal, v.8, n.4, p.267-275, 2007.

COSTA, M.C.; FLAIBAN, K.K.M.C.; CONEGLIAN, M.M.; FEITOSA, F.L.F.; BALARIN, M.R.S.; LISBÔA, J.A.N. Transferência de imunidade passiva em bezerros das raças Nelore e Limousin e proteinograma sérico nos primeiros quatro meses de vida.

Pesquisa Veterinária Brasileira, v.28, n.9, p.410-416, 2008.

COVERDALE, J.A.; TYLER, H.D.; QUIGLEY, J.D.; BRUMM, J.A. Effect of various levels of forage and form of diet on rumen development and growth in calves. Journal of Dairy Science, v.87, n.8, p.2554-2562, 2004.

CRUYWAGEN, C.W., JORDAAN, I.; VENTER, L. Effect of lactobacillus acidophilus supplementation of milk replacer on preweaning performance of calves. Journal of Dairy Science, v.79, p.483-486, 1996.

ENRÍQUEZ, D.H.; UNGERFELD R.; QUINTANS G.; GUIDONI A.L.;

HÖTZEL M.J. The effects of alternative weaning methods on behavior in beef calves. Livestock Science, v.128, p.2027, 2010.

GREENWOOD, R.H.; MORRIL, J.L.; TITGEMEYER, C. Using dry feed intake as a percentage of initial body weight as a weaning criterion. Journal of Dairy Science, v.80, p.2542-2546, 1997.
GULLIKSEN, S.M.; JOR, E.; LIE , K.I.; HAMNES, I.S.; LØKEN, T.; ÅKERSTEDT, J.; ØSTERÅS, O. Enteropathogens and risk factors for diarrhea in Norwegian dairy calves. Journal of Dairy Science, v.92, p.5057-5066, 2009.

HAGA, S.; FUJIMOTO, S.; YONEZAWA, T.; YOSHIOKA, K.; SHINGU, H.; KOBAYASHI, Y.; TAKAHASHI, T.; OTANI, Y.; KATOH, K.; OBARA, Y. Changes in hepatic key enzymes of dairy calves in early weaning production systems. Journal of Dairy Science, v. 91, n.8, p.3156-3164, 2008.

HALEY, D.B.; BAILEY D.W.; STOOKEY J.M. The effects of weaning beef calves in two stages on their behavior and growth rate. Journal of Animal Science, v.83, p.2205-2214, 2005.

HAYASHI, H.; KAWAI, M.; NONAKA, I.; TERADA, F.; KATOH, K.; OBARA, Y. Development changes in the kinetics of glucose and urea in Holstein calves. Journal of Dairy Science, v.89, n.5, p.1654-1661, 2006.

HILL, S.R.; HOPKINS, B.A.; DAVIDSON, S.; BOLT, S.M.; DIAZ, D.E.; BROWNIE, C.; BROWN, T.; HUNTINGTON, G.B.; WHITLOW, L.W. The addition of cottonseed hulls to the starter and supplementation of live yeast or mannanoligosaccharide in the milk for young calves. Journal of Dairy Science, v.92, p.790-798, 2009.

JENNY, B.F.; VANDIJK, H.J.; COLLINS, J.A. Performance and fecal flora of calves fed a Bacillus subtilis concentrate. Journal of Dairy Science, v.74, n.6, p.1968-1973, 1991. 
Rev. Bras. Saúde Prod. Anim., Salvador, v.17, n.2, p.249-261 abr./jun., 2016 http://www.rbspa.ufba.br ISSN 15199940

KELLEY, K.W. Stress and immune function: A bibliographic review. Annales de Recherches Vétérinaires, v.11, n.4, p.445-478, 1980.

KHAN, M.A.; LEE, H. J.; LEE, W.S.; KIM, H.S.; KIM, S.B.; KI, K.S.; HA, J.K.; LEE, H.G.; CHOI, Y. J. Pre- and postweaning performance of holstein female calves fed milk through stepdown and conventional methods.

Journal of Dairy Science, v.90, p.876$885,2007$.

KREHBIEL, C.R.; RUST, S.R.; ZHANG, G.; GILILAND, S.E. Bacterial direct-fed microbials in ruminant diets: Performance response and mode of action. Journal of Animal Science, v.81, n.2, p.E120-E132, 2003.

LARSON, L.L.; OWEN, F.G.; ALBRIGHT, J.L.; APPLEMAN, R.D.; LAMB, R.C.; MULLER, L.D. Guidelines toward more uniformity in measuring and reporting calf experimental data. Journal of Dairy Science, v.60, n.6, p.989-991, 1977.

LEONARD, H.P. Criterios de selección y mecanismos de acción de cepas de levedura para uso como aditivo probiótico em animales. Instituto Cubano de Investigaciones de los Derivados de la Caña de Azúcar, n.13, p.38-45, 2008.

LIMA, P.O.; CÂNDIDO, M.J.D.; QUEIROZ, M.G.R.; FERREIRA, J.M.; MODESTO, E.C.; LIMA, R.N.; GOMES, J.M.C.; AQUINO, R.M.S. Parâmetros séricos de bezerros submetidos a diferentes tipos de dietas líquidas. Revista Brasileira de Saúde e Produção Animal [online], v.13, n.2, p.529-540, 2012
MATOS, B.C. Uso de aditivos na pecuária leiteira: revisão. PUBVET, v.2, n.9, 2008.

MILLEMANN, Y. Diagnosis of neonatal calf diarrhea. Revue de Médecine Veterinaire, v.160, p.404409, 2009.

MORRILL, J.L.; MORRILL, J.M.; FEYERHERM, A.M. Plasma proteins and a problotlc as ingredients in milk replacer. Journal of Dairy Science, v.78, p.902-907, 1995.

MOTA, R.A.; SILVA, K.P.C.; FREITA, M.F.L.; PORTO, W.J.N.; SILVA, L.B.G. Utilização indiscriminada de antimicrobianos e sua contribuição a multiresistência bacteriana. Brazilian Journal of Veterinary Research and Animal Science, v.42, n.6, p.465-467, 2005.

PAES, P.R.O.; GONÇALVES, R.C.; BARIONI, G.; LEME, F.O.P.; MELO, M.M.; CRUZ, M.L. O leucograma como indicador de estresse no desmame e no transporte rodoviário de bovinos da raça Nelore. Ciências Agrárias, v.33, n.1, p.305-312, 2012.

PENHA, L.A.C.; PARDO, P.E.; KRONKA, S.N.; REIS, L.S.L.S.; OBA, E.; BREMER-NETO, H. Effects of probiotic supplementation on liveweight gain and serum cortisol concentration in cattle. Veterinary Record, v.168, p.538, 2011.

QUIGLEY III, J.D.; CALDWEEL, L.A.; SINKS, G.D.; HEITMANN, R.N. Changes in blood glucose, nonesterified fatty acids, and ketones in response to weaning and feed intake in young calves. Journal of Dairy Science, v.74, n.1, p.250-257, 1991. 
Rev. Bras. Saúde Prod. Anim., Salvador, v.17, n.2, p.249-261 abr./jun., 2016 http://www.rbspa.ufba.br ISSN 15199940

RINCKER, L.E.D.; VANDEHAAR, M.J.; WOLF, C.A.; LIESMAN, J.S.; CHAPIN, L.T.; NIELSEN, M.S.W.

Effect of intensified feeding of heifer calves on growth, pubertal age, calving age, milk yield, and economics.

Journal of Dairy Science, v.94, n.7, p.3554-3567, 2011.

SANDERS, M.E. Probiotics: definition, sources, selection, and uses. Clinical

Infectious Diseases, v.46, p.S58-S61, 2008.

SANTOS, F.H.R.; DE PAULA, M.R.; LEZIER, D.; SILVA, J.T.; SANTOS, G.; BITTAR, C.M.M. Essential oils for dairy calves: effects on performance, scours, rumen fermentation and intestinal fauna. Animal, v.9, p.958965, 2015.

\section{SAS INSTITUTE. Base SAS ${ }^{\circledR} 9.4$} procedure user's guide: statistical procedures. 3rd ed. Cary, 2013. 482p.

SHINGU, H.; HAYASHI, H.; TOUNO, E.; OSHIBE, A.; KUSHIBIKI, S.; ODA, S.; KATOH K.; OBARA, Y. Characteristics of developmental changes in the kinetics of glucose and urea in Japanese Black calves: Comparison with Holstein calves. Journal of Animal Science, v.85, p.2910-2915, 2007.

SILVA, J.T.; BITTAR, C.M.M.; FERREIRA, L.S. Desempenho e desenvolvimento ruminal em resposta ao fornecimento de substâncias húmicas para bezerros leiteiros em sistema de desaleitamento precoce. Acta Scientiarum. Animal Sciences, v.33, n.4, p.395-401, 2011.

SNEL-OLIVEIRA, M.V.; WETZELGASTAL, D.; SARTORI, R.; NEVES, J.P. Influência de procedimentos ginecológicos frequentes no desempenho produtivo e reprodutivo de fêmeas bubalinas Murrah. Ciência Animal Brasileira, v.14, n.4, p.468472, 2013.

TIMMERMAN, H.M.; MULDER, L.; EVERTS, H.; VAN ESPEN, D.C.; VAN DER WAL, E.; KLAASSEN, G.; ROUWERS, S.M.G.; HARTEMINK, R.; ROMBOUTS, F.M.; BEYNEN, A.C. Health and growth of veal calves fed milk replacers with or without probiotics. Journal of Dairy Science, v.88, n.6, p.2154-2165, 2005.

UNITED STATES DEPARTMENT OF AGRICULTURE - USDA. Part I:

Reference of dairy cattle health and management practices in the United States. Fort Collins, 2007. p.53.

YARI, M.; NIKKHAH, A.; ALIKHANI, M.; KHORVASH, M.; RAHMANI, H.; GHORBANI, G.R. Physiological calf responses to increased chromium supply in summer. Journal of Dairy Science, v.93, p.4111-4120, 2010.

Data de recebimento: 01/09/2015

Data de aprovação: 06/04/2016 